\title{
BMJ Open Use of antimicrobial dressings in England and the association with published clinical guidance: interrupted time series analysis
}

\author{
Louise Hussey, ${ }^{1,2}$ Susan J Stocks, ${ }^{3}$ Paul Wilson, ${ }^{\circledR 2,4}$ Jo C Dumville, ${ }^{1,2}$ \\ Nicky Cullum ${ }^{1,2,5}$
}

To cite: Hussey L, Stocks SJ, Wilson P, et al. Use of antimicrobial dressings in England and the association with published clinical guidance: interrupted time series analysis. BMJ Open 2019;9:e028727. doi:10.1136/ bmjopen-2018-028727

\section{- Prepublication history and} additional material for this paper are available online. To view these files, please visit the journal online (http://dx.doi. org/10.1136/bmjopen-2018028727).

Received 15 January 2019 Revised 10 June 2019 Accepted 14 June 2019

\section{Check for updates}

(c) Author(s) (or their employer(s)) 2019. Re-use permitted under CC BY-NC. No commercial re-use. See rights and permissions. Published by BMJ.

For numbered affiliations see end of article.

\section{Correspondence to}

Dr Louise Hussey;

louise.hussey@manchester. ac.uk

\section{ABSTRACT}

Objectives In healthcare systems, practices and products of unproven value and cost-effectiveness can decrease value and increase waste. Using the management of complex wounds, this study investigates temporal trends in the use of antimicrobials dressings, places this in the context of available evidence and discusses the potential impacts on the UK National Health Service (NHS).

Design Secondary descriptive and interrupted time series (ITS) analysis of NHS prescription data.

Setting Prescribing Cost Analysis (PCA) details all NHS prescriptions dispensed in the community in England. Interventions An ITS design was used to compare annual changes in the expenditure and use of antimicrobial and non-antimicrobial dressings before and after the publication of the 'intervention' of key evidence-based Scottish Intercollegiate Guidelines Network (SIGN) guidance in 2010 .

Primary and secondary outcome measures Trends in use and expenditure of antimicrobial dressings in relation to published clinical guidance.

Results There was a large increase in the prescribing of, and expenditure on, antimicrobial wound dressings between 1997 and 2016. In 1997, the total number of dressings prescribed was 5792700 ; increasing to 11447102 in 2009 with expenditure increasing from $£ 1960386$ to $£ 32841263$. During the year of the SIGN intervention (2010), there was a significant drop in the use of silver but there was no consistent ongoing reduction from 2011 to 2015.

Conclusions Prescribing data can be used to identify products of unproven benefit, which also impose a significant financial burden. This study quantifies the huge increase in the use of antimicrobial wound dressings over a 20-year period despite the lack of compelling evidence to support their routine use. There is some suggestion, however that the use and expenditure decreased after the publication of key guidance. Routine data can be used to as part of more systematic efforts to increase value and reduce waste in health systems.

\section{INTRODUCTION}

Resource-constrained healthcare systems face increasing demands due to ageing populations, emerging medical conditions, modern
Strengths and limitations of this study

- The first research study identified that clearly reports the temporal changes in the use of relatively costly wound care products in the UK community over several years.

- Techniques such as interrupted time series analysis of prescribing data can be used to explore and illustrate the relationship between treatment choice and the contemporaneous availability of evidence about clinical and cost-effectiveness.

- Interrupted time series analysis has been used to explore the possible impact of a national clinical guidelines on the use of antimicrobial dressings.

- The prescribing data are not wound-specific and limited to English community prescriptions; however, the community is where most complex wounds are treated.

- A summary of the general status of evidence helps provide important contextual information in which to interpret the data.

lifestyles and advances in technology. ${ }^{1}$ It is imperative we increase the value of healthcare and improve outcomes for patients relative to costs. ${ }^{2}$ Clinical practice should, where possible, be informed by research evidence to ensure that limited funds are spent on resources and treatments with proven beneficial outcomes; in some cases, the deimplementation of contradicted and unproven practices is required in order to increase value and reduce waste. ${ }^{3-5}$

The management of complex wounds such as leg, foot and pressure ulcers places a huge burden on healthcare resources. Although these wounds are managed in a variety of healthcare settings, in the UK the majority of care is delivered by community nurses. ${ }^{6}$ These open wounds are usually covered with a wound dressing, and there are many options available ranging from simple gauzes to advanced dressings that have different 
absorptive properties such as foam, hydrocolloid and alginates. ${ }^{7}$ The availability of such a wide range of dressings can cause decision uncertainty among practitioners, which in turn is reflected in a wide variation in terms of antimicrobial dressing use within and across different healthcare providers. ${ }^{68}$

Wound dressings are classed as external medical devices and, as such, require a lower level of evidence to support marketing authorisation. The European regulatory framework for evaluating and regulating medical devices only requires manufacturers to demonstrate that new devices are safe and fit for purpose. ${ }^{9}$ A new Medical Device Regulation is due to be fully applied in 2020 and will replace the European Union's current Medical Device Directive and aims to ensure greater confidence in the effective protection of public health and patient safety. ${ }^{10}$ However, to date, new dressing products come to market relatively rapidly and are not always supported by evidence of effectiveness. ${ }^{11} 12$

The mid-1990s saw an increase in the availability of dressings claiming to have valuable antimicrobial properties due to the inclusion of ingredients such as silver, honey and iodine. Such dressings were developed and promoted for the prevention and treatment of wound infection and to ultimately improve wound healing. ${ }^{13}$ Generally, antimicrobial dressings are more expensive to buy than their non-antimicrobial counterparts. This study aimed to investigate temporal trends in the use of antimicrobials dressings and place use in the context of available evidence. Specifically, we aimed to address:

- How many antimicrobial dressings are used by National Health Service (NHS) community services in England and how much does this cost?

- How has the use of antimicrobial dressings changed over time?

- What impact has the publication of evidence-based guidance had on trends in antimicrobial dressing?

In addition to these analyses, we also present this antimicrobial use and cost data in the context of contemporaneously available systematic review findings and other clinical guideline recommendations to examine whether trends may reflect any resulting change in practice.

\section{METHODS}

\section{Extraction of data on antimicrobial dressing use and cost}

UK NHS Prescribing Cost Analysis (PCA) is freely available information accessed from 'NHS Digital' and details all NHS prescriptions dispensed in the community in England on an annual basis. ${ }^{14}$ This includes all prescriptions dispensed by pharmacists, doctors and appliance contractors (eg, suppliers of stoma and continence care equipment). PCA data give detail of the quantity (measured in units depending on the formulation of the product (eg, one tablet, pack or dressing)) and also the net ingredient cost (NIC) (expenditure on the product before discounts, not including any dispensing costs or fees). The drugs/dressings/devices are listed by British
National Formulary (BNF) therapeutic class. ${ }^{15}$ PCA data are produced per annum, and an Excel file for each year is available for download on the NHS Digital website. ${ }^{14}$ We extracted annual expenditure and quantity data from BNF Chapter 20 (dressings), Section 3 (wound management and other dressings) and Section 4 (gauzes and gauze tissue) for a 20-year period (1997 to 2016). We searched for terms and brand names in four antimicrobial dressings categories: silver, honey, iodine and other antimicrobial dressings. ${ }^{15}$ 'Other' antimicrobial dressings include those containing agents other than those specified above, such as polyhexamethylene biguanide hydrochloride and chlorohexidine. To ensure accuracy, this identification and categorisation process was carried out independently by two authors and any discrepancies resolved through discussion. The quantity and expenditure (NIC) for 1997 to 2016 were plotted and presented as totals per annum. We chose this period of data analysis in part due to rounding to provide analyses for complete decades but also to include the point in time when honey and silver dressings first appeared in the data. Data for the years 1992 to 1996 were checked to ensure that there were no records of honey-containing or silver-containing wound dressings prior to 1997.

\section{Identification of relevant guidelines and systematic reviews}

First, we located key national guidelines relevant to the use of wound dressings in the community. We restricted our search to recognised UK-based producers of highquality, evidence-based guidelines who follow a transparent, rigorous process of guideline production-that is, The National Institute for Health and Care Excellence (NICE), the Scottish Intercollegiate Guidelines Network (SIGN) and relevant professional bodies such as the Royal Colleges. Second, we searched for relevant Cochrane systematic reviews that follow a rigorous and transparent process and they are freely available and highly accessed in the UK. Recommendations regarding the use of antimicrobial dressings were detailed in the published clinical guidance.

\section{Interrupted time series (ITS) analysis}

An ITS design was used to compare annual changes in the expenditure and use of antimicrobial and non-antimicrobial wound dressings, focusing first on all antimicrobial dressings and then just those containing silver. The time periods to be compared were selected a priori and covered 2005 to 2009 , with 2010 as the intervention point and the following 5 years as the postintervention period (2011 to 2015). We chose 2010 as the intervention point since this was when the SIGN Guidelines ${ }^{16}$ for the treatment of venous leg ulcers were published, which itself was shortly after publication of a major trial of silver dressings for the treatment of venous leg ulcers. ${ }^{17}$ In 2010, the SIGN Guidelines were the first new, national (UK) complex wound-related guidelines to be published for a number of years and subsequent to the introduction of silver dressings. The selected 5-year time periods were kept close to the 


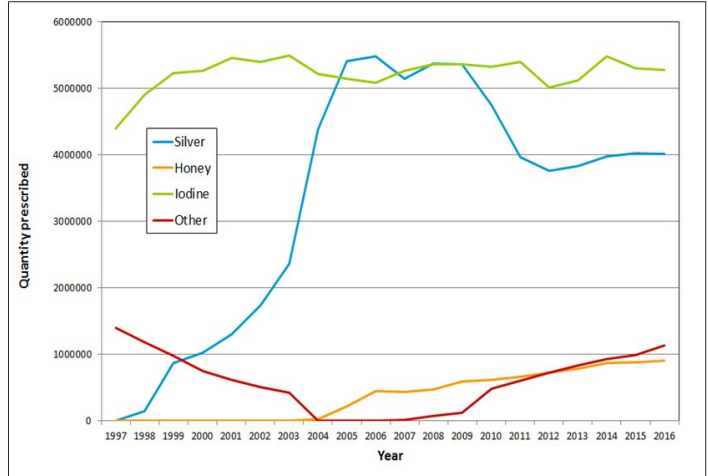

Figure 1 The quantity prescribed per annum of silver, honey, iodine and other antimicrobial dressings prescribed in the community in England (1997 to 2016).

intervention point (ie, the guideline publication date) to reduce potential confounding by events occurring at a more distant time, while still giving sufficient data points for analysis. Ordinary least squares regression was used to estimate the temporal trends before, during and after the interventions with presentation of Newey-West standard errors to handle autocorrelation. The Cumby-Huizinga test was used to investigate autocorrelation. The analysis was undertaken in Stata 14 using the $i t s a$ command. ${ }^{18}$ We used three categories to make the results easier to read, therefore if the level of significance is labelled:

$\mathrm{P}<0.001$, then the result is as it reads.

$\mathrm{P}<0.05$, significance is less than 0.05 but greater than $0>0.001$.

$\mathrm{P}<0.1$, significance is less than 0.1 but greater than 0.05 .

\section{Patient and public involvement}

Patients and the public were not involved in the design or planning of the study.

\section{Ethical approval}

Ethical approval was not required as this study is based on secondary analysis of freely available PCA information.

\section{RESULTS}

\section{Trends in dressing use and expenditure}

From 1997 to 2016, there was an increase in the use of (figure 1) and expenditure on (figure 2) antimicrobial dressings. In terms of quantity prescribed 5792700 antimicrobial dressings were prescribed in 1997 compared with 11029304 in 2006 and 11344471 in 2016.

In 1997, the only antimicrobial dressings included in the prescription data were those containing iodine or chlorhexidine (classed here as an 'other antimicrobial dressing'). Silver-containing dressings first appeared in the prescription data in 1998 and honey dressings in 2004. While iodine dressings have been prescribed relatively consistently between 1998 and 2006, during the same period the quantity of silver dressings prescribed increased from 143600 to 5485684 .

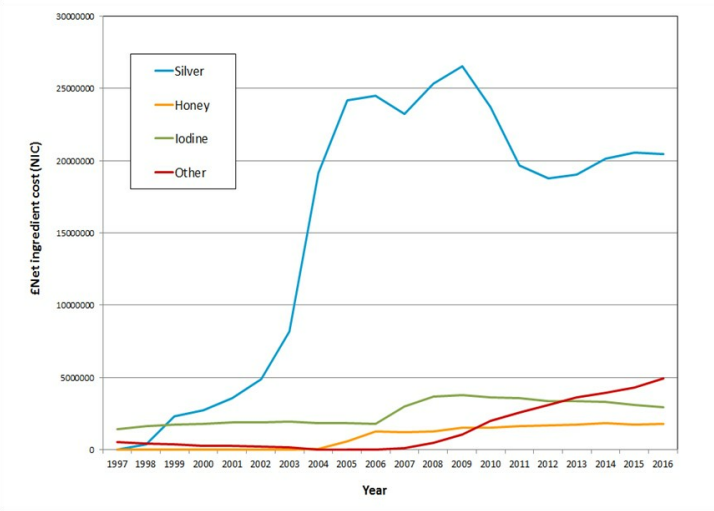

Figure 2 The net ingredient cost (NIC) (total expenditure) per annum of silver, honey, iodine and other antimicrobial wound dressings prescribed in the community in England (1997 to 2016).

The increase in quantity of antimicrobial dressing use is matched by changes in expenditure over time (figure 2). In 1997, the total expenditure on antimicrobial dressings was $£ 1960386$, increasing to a high of $£ 32841263$ in 2009 (an almost 17-fold increase). The most notable increase in annual expenditure was for silver dressings where annual spend increased year on year from 1998 onwards reaching a peak in 2009 with annual expenditure of over $£ 26.5$ million.

Figure 3 plots antimicrobial dressing prescriptions (quantity and expenditure) as a proportion of all wound dressings prescribed in the community in England. Over time antimicrobial dressings have comprised a greater proportion of all dressings used and an even greater share of expenditure.

\section{Summary of relevant evidence synthesis and guidelines on antimicrobial dressing use for complex wounds}

Table 1 outlines the key publications summarising evidence and giving guidance on the use of antimicrobial dressings in the treatment of complex wounds. The first UK guidance we found was published in $1998^{19}$ and suggested little or no good research evidence

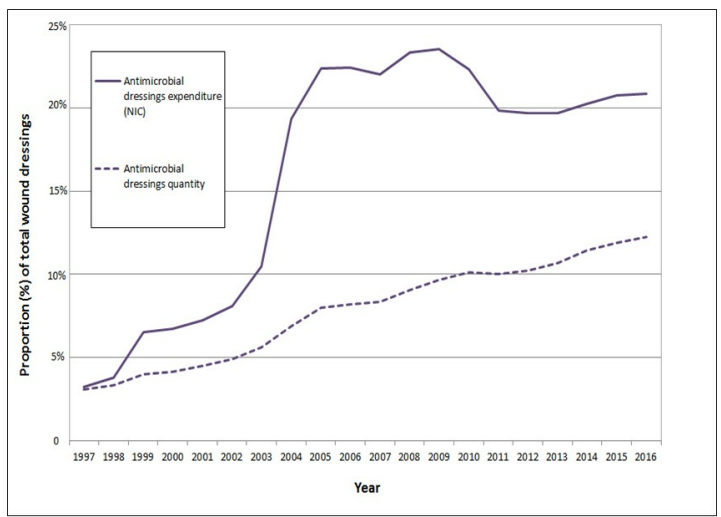

Figure 3 The quantity and net ingredient cost (NIC) (total expenditure) per annum of antimicrobial dressings as a proportion of all dressings prescribed in the community in England (1997 to 2016). 
Table 1 Published evidence giving recommendations on the use of antimicrobial dressings for treatment of complex wounds

\begin{tabular}{|c|c|c|c|c|c|}
\hline Code & Published guidance & Month & Year & $\begin{array}{l}\text { Evidence for use of antimicrobial } \\
\text { dressings }\end{array}$ & Recommendation or conclusions \\
\hline A & $\begin{array}{l}\text { Clinical Practice } \\
\text { Guidelines: The } \\
\text { nursing management } \\
\text { of patients with } \\
\text { venous leg ulcers }^{19}\end{array}$ & \multicolumn{2}{|c|}{$\begin{array}{l}\text { First published 1998, } \\
\text { updated } 2005 \text { and } \\
2006\end{array}$} & $\begin{array}{l}\text { The evidence in the guidance } \\
\text { for 'Antimicrobial agents versus } \\
\text { placebo or standard care' is based } \\
\text { on a systematic review by O'Meara } \\
\text { published in } 2000 \text { reviewing } 14 \\
\text { RCTs. The RCTs were small and } \\
\text { of poor quality, therefore no firm } \\
\text { conclusions could be drawn. }\end{array}$ & $\begin{array}{l}\text { Dressings must be simple, low } \\
\text { adherent and acceptable to the } \\
\text { patient. Cost-effectiveness of } \\
\text { leg ulcer dressings should be } \\
\text { determined by their ability to stay } \\
\text { in place for up to a week }\end{array}$ \\
\hline$B$ & $\begin{array}{l}\text { Cochrane review: } \\
\text { Topical silver for } \\
\text { treating wound } \\
\text { infection }\end{array}$ & January & 2007 & $\begin{array}{l}\text { This assessed topical silver } \\
\text { products (creams or dressings) for } \\
\text { the prevention of wound infection } \\
\text { through the evaluation of } 26 \text { RCTs. } \\
\text { The majority of studies found no } \\
\text { statistical difference in infection } \\
\text { rates between silver and non-silver } \\
\text { dressings. Most of the trials were } \\
\text { small and of poor quality. }\end{array}$ & $\begin{array}{l}\text { There is insufficient evidence to } \\
\text { support the use of silver dressings } \\
\text { as they did not reduce infection or } \\
\text { promote wound healing }\end{array}$ \\
\hline C & $\begin{array}{l}\text { Cochrane review: } \\
\text { Honey as a topical } \\
\text { treatment for } \\
\text { wounds }^{40}\end{array}$ & \multicolumn{2}{|c|}{$\begin{array}{l}\text { First published 2008, } \\
\text { updated } 2015\end{array}$} & $\begin{array}{l}26 \text { trials were identified. Two of } \\
\text { high quality found that honey } \\
\text { dressings heal partial thickness } \\
\text { burns more quickly than } \\
\text { conventional dressings. Other } \\
\text { trials either showed no difference } \\
\text { between treatments or were based } \\
\text { on low-quality evidence }\end{array}$ & $\begin{array}{l}\text { The evidence for the effect of } \\
\text { honey compared with other } \\
\text { dressings is low quality, and } \\
\text { therefore not robust enough basis } \\
\text { for decision making }\end{array}$ \\
\hline $\mathrm{D}$ & $\begin{array}{l}\text { SIGN guidance: } \\
\text { Management of } \\
\text { venous leg ulcers }^{16}\end{array}$ & August & 2010 & $\begin{array}{l}\text { The recommendations for silver } \\
\text { dressings are based on a Cochrane } \\
\text { review in } 2007 \text { by Vermeulen et } \\
\text { al and the VULCAN trial in } 2009 \text {. } \\
\text { These found insufficient evidence } \\
\text { to show improved healing rates for } \\
\text { wounds treated with silver dressings } \\
\text { compared with other types of } \\
\text { dressings }\end{array}$ & $\begin{array}{l}\text { Guidance concludes that } \\
\text { simple non-adherent dressings } \\
\text { are recommended for VLU* } \\
\text { management. Silver dressings are } \\
\text { not }\end{array}$ \\
\hline E & $\begin{array}{l}\text { NICE guidance: } \\
\text { Pressure ulcers: } \\
\text { prevention and } \\
\text { management }^{41}\end{array}$ & April & 2014 & $\begin{array}{l}\text { Alginate versus silver alginate. No } \\
\text { statistical difference, very low- } \\
\text { quality evidence }\end{array}$ & $\begin{array}{l}\text { The evidence did not allow for a } \\
\text { recommendation of any specific } \\
\text { type of dressing. Recommends a } \\
\text { dressing that promotes an optimal } \\
\text { healing environment rather than a } \\
\text { specific type }\end{array}$ \\
\hline $\mathrm{F}$ & $\begin{array}{l}\text { NICE guidance: } \\
\text { Diabetic foot } \\
\text { problems: prevention } \\
\text { and management }{ }^{42}\end{array}$ & August & 2015 & $\begin{array}{l}\text { Included one RCT comparing iodine- } \\
\text { impregnated dressings with others; } \\
\text { found no difference in healing rates }\end{array}$ & $\begin{array}{l}\text { Take into account clinical } \\
\text { assessment of the wound and } \\
\text { patient preference. Use dressing of } \\
\text { lowest acquisition cost appropriate }\end{array}$ \\
\hline G & $\begin{array}{l}\text { Chronic wounds: } \\
\text { Advanced wound } \\
\text { dressings and } \\
\text { antimicrobial } \\
\text { dressings }^{11}\end{array}$ & March & 2016 & $\begin{array}{l}\text { Gives an overview of previously } \\
\text { published evidence and summarises } \\
\text { research findings }\end{array}$ & $\begin{array}{l}\text { There is little good-quality } \\
\text { evidence to support the use of } \\
\text { antimicrobial dressings. Healthcare } \\
\text { professionals should choose the } \\
\text { least costly option, which will } \\
\text { provide the optimal environment } \\
\text { for the type of wound and stage of } \\
\text { healing }\end{array}$ \\
\hline
\end{tabular}

*Venous leg ulcers

NICE, The National Institute for Health and Care Excellence; RCT, randomised controlled trial ; SIGN, Scottish Intercollegiate Guidelines Network; VLU, Venous leg ulcers. 
that using antimicrobial dressings influenced wound outcomes. Guidance universally recommends using simple, non-adherent wound dressings for complex wounds and agrees that there is little research evidence to suggest that antimicrobial dressings are clinically or cost-effective.

\section{ITS before and after publication of the SIGN guidance in 2010} Data from 2005 to the intervention year-2010

The results of the ITS analysis for expenditure on antimicrobial dressings from 2005 to 2015 are shown in table 2 and online supplementary appendix 1 . £25.9 million (95\% CIs, £24.4 to £27.5) was spent on antimicrobial dressings in 2005 , followed by an increase in spending of, on average, £1.6 million per year ( $£ 1.0$ to $£ 2.1$ ) until 2009. In 2010 (the year of the SIGN guidance publication and 1 year after publication of the VULCAN study), there was a reduction in the expected spending on antimicrobial dressings (based on the preintervention trend) of $-£ 5.2$ million ( $-£ 8.6$ to $-£ 1.7$, see online supplementary appendix $1 \mathrm{~A}$ ); this reduction was largely driven by a reduction in silver dressing spend (see table 2 and online supplementary appendix 1B (expenditure) and $\mathrm{C}$ (use)). There was no corresponding significant reduction in expenditure on non-antimicrobial dressings in 2010 ( $£ 0.9$ million; $-£ 4.8$ to $£ 3.0$, table 2 and online supplementary appendix 1D).

Trends in quantity and expenditure of dressing use across the preintervention and postintervention period

Prior to the SIGN intervention during 2005 to 2009, the use of antimicrobial dressings (by quantity) was significantly increasing by 170000 dressings per year (110000 to 230000 ) assuming a linear trend, but following the SIGN intervention during 2011 to 2015 the increasing trend slowed and was no longer significant (increasing by 70000 dressings per year; $-180,000$ to 310000 ). This change in the trend after the SIGN intervention compared with before the SIGN intervention was not significant (a reduction in average annual use 100000 dressings per year relative to the pre-SIGN trend; -370 000 to 160000 ). For a graphical illustration, see online supplementary appendix $1 \mathrm{E}$.

This pattern was significantly different from the annual decrease in use of non-antimicrobial dressings, which continuously declined from 2005 to 2015 (table 2 and comparing panels $\mathrm{E}$ and $\mathrm{F}$ in online supplementary appendix 1). Taking the preintervention trend as the counterfactual, the mean annual reduction in expenditure postintervention was £1.6 million $(-£ 2.9$ to $-£ 0.2)$ for antimicrobial dressings and £2.1 million ( $£ 3.0$ to -£1.2) for non-antimicrobial dressings (not a statistically significant difference that is, the higher cost of antimicrobial dressings meant that they contributed more or less equally to the cost reductions when compared with non-antimicrobial dressings even though the quantities used were lower, see table 2).
Differences between dressing use and expenditure in the postintervention period

Comparing the use of antimicrobial and non-antimicrobial dressings in the postintervention period (from 2011 to 2015), we observe increasing expenditure on non-antimicrobials dressings with decreased use (by quantity). Data show that the increasing trend for expenditure on non-antimicrobial dressings is significantly different to the flat trend for antimicrobial dressings (table 2).

\section{DISCUSSION}

\section{Summary of main findings}

Prescription of antimicrobial wound dressings in the UK has increased since 1997. This increase is particularly notable for silver-containing dressings. The Clinical guidance and Cochrane reviews presented in table 1 show that there is no research evidence to support the routine use of antimicrobial dressings for complex wounds. Thus, there has been a large increase in the use of silver-containing wound dressings that cannot be explained by the contemporaneous research evidence. Historic use of silver, iodine and honey in wound healing is well documented. ${ }^{20-22}$ It has been suggested that resurgence in the use of these topical agents may be partly due to concerns about antibiotic-resistant bacteria and the need to reduce antibiotic prescribing. ${ }^{23}$

Our analysis shows that, following a period of rapid increase in antimicrobial dressing prescribing and expenditure, the publication of SIGN guidelines for venous leg ulcer management (2010) was followed by a significant reduction (both in cost and number of items). There was no commensurate change in the prescribing of other dressings. It is not clear why the reduction in antimicrobial use was not matched by an increase in use of other dressings to compensate for this differential use. A possible explanation may be that other dressings were being taken from stock resources and so are not counted in the prescribing data. Being in stock means that the products are obtained directly via procurement in bulk-this would be most common for standard dressings. We note that while prescribing of silver-containing dressings reduced, there appears to have been an increase in prescribing of honey, iodine and 'other' antimicrobial dressings. If these trends are to be considered, in some part, to be an impact of the publication of the SIGN guideline, the guideline had more of an impact on the use of silver dressings than of other antimicrobial dressings. A potential explanation for this differential effect on antimicrobial dressing prescribing lies in the strength of the recommendations. The SIGN guidelines graded recommendations A to D based on the quality of the evidence and these differed for different dressings. The recommendation for silver dressings was graded A, that for honey was graded B and that for iodine dressings was unclassified. ${ }^{16}$ It may be that the strength of the recommendation for not 


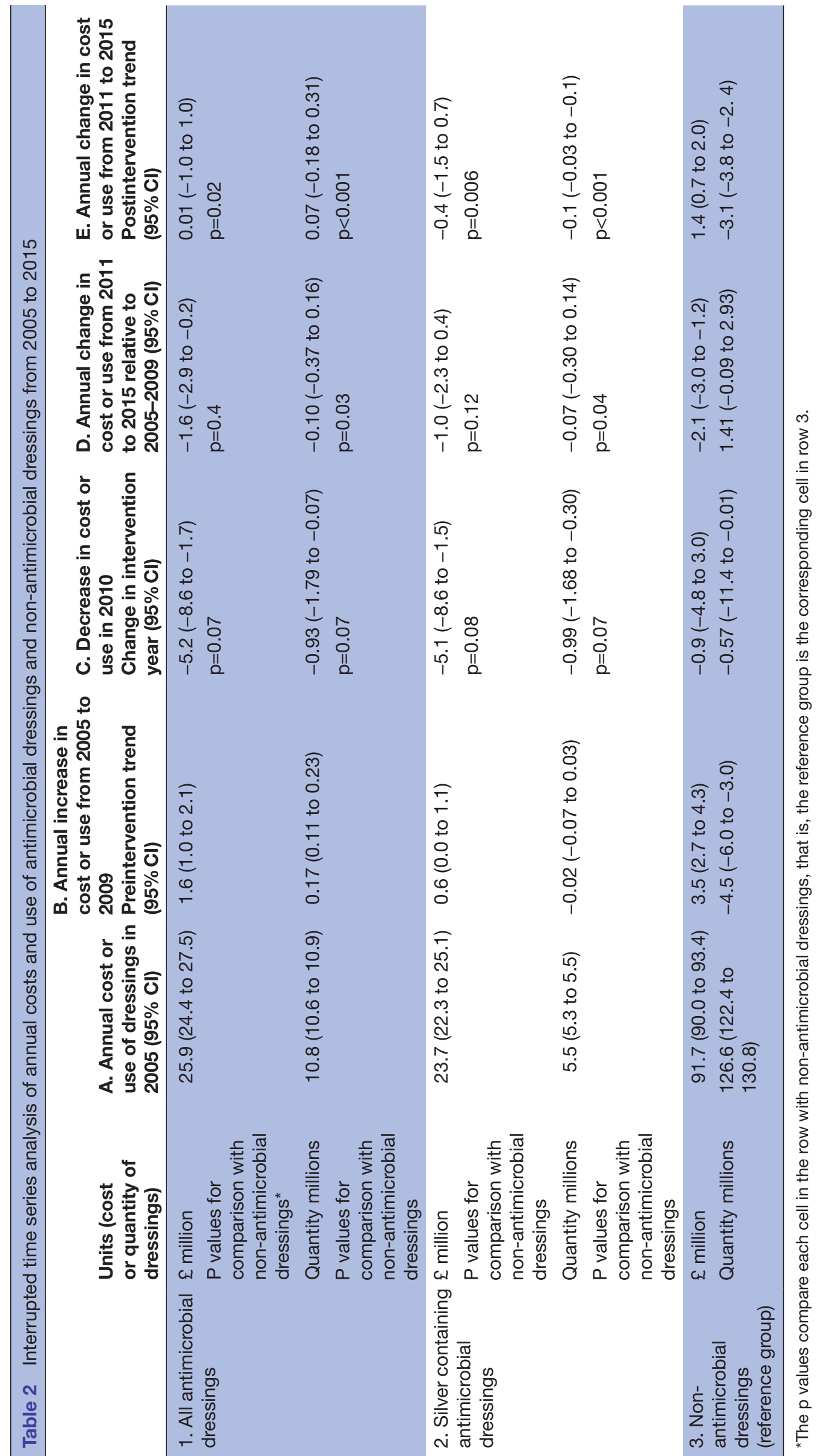


using silver dressings was considered more compelling or that this recommendation had a greater effect because of the higher cost of silver dressings and the potential savings.

When looking across the entire study period, our analysis suggests that the total number of dressings used per annum may be decreasing. Conversely, total expenditure on dressings appears to be increasing. ${ }^{14}$ The reasons for this pattern require further exploration-potential areas to explore include the use of other medical devices or advanced dressings, which are relatively expensive but may require less frequent changes ${ }^{13}$ and/or the potential for increased unit prices for non-antimicrobial dressings.

\section{Treatment-related decision making in wound care}

It is widely acknowledged that the process of decision making is highly contingent and context dependent, ${ }^{24}$ particularly so in community and primary care. ${ }^{25}$ Reliable sources of evidence-based information including clinical guidelines and systematic reviews can influence decision making especially where a single clear message is conveyed to professional audiences who themselves are aware that a change in practice is required. ${ }^{26} \mathrm{~A}$ national evaluation of the implementation of NICE guidance found that recommendations are more likely to be adopted when there is strong professional support, clear guidance and no increased or unfunded costs. ${ }^{26}$ We know that the clinical decisions of community nurses are often based on experiential rather than research knowledge ${ }^{27}$ and that 'human sources' are often preferred to written guidance. ${ }^{28}$ It seems clear from the temporal trends that the increases in dressing use are not driven by knowledge of the research evidence. ${ }^{29}$ This may suggest that any action aimed at implementing evidence-based guidance within community nursing may benefit from being more focused on the type of change necessary to generate a reduction in specific prescribing practices such as restriction of formulary options and routine monitoring and feedback of individuals prescribing practice to ensure adherence to organisational policies. ${ }^{30}$

Patient preference may also play a part in dressing selection. Research has shown that healing time was ranked by patients as the most important factor (compared with other factors such as dressing change frequency and pain). ${ }^{31}$ Choosing Wisely is a global initiative to address issues such as patient and clinician preferences and making better decisions about care with the aim that this will help avoid tests, treatments or procedures that are unlikely to be of benefit. Choosing Wisely UK is led by the Academy of Medical Royal Colleges and as yet does not encompass nursing as a profession or have any guidance focused on the management of complex wounds. ${ }^{32} 33$

The widespread availability of wound care products of apparent low or no clinical value is in part reflective of the threshold for evidence necessary for marketing authorisation of devices. ${ }^{9}$ Because the threshold of evidence is low, there is little or no incentive for manufacturers to demonstrate that their devices are clinically effective. Research showing how evidence is used to support claims made in product advertisements within two wound care journals found just $35 \%$ of claims about the benefits of a product cited supporting evidence. When these sources of evidence were investigated, the cited evidence did not support the claim being made in $56 \%$ of cases. ${ }^{12}$ The emphasis is therefore on incremental product development and innovation. Adopting a medical device when there is little or no evidence to support its use may then in turn lead to a reduction in the likelihood of further relevant research as the innovation becomes standard and integrated into care. ${ }^{4}$

Rothery et al suggest that rather than binary choice of adopt or select, policy decisions on innovation introduction may be helped by guidance recommending either options of 'only in research' or 'approval with research'. ${ }^{34}$ The former allowing further research to establish the value of an innovation before wider access and the latter granting the possibility of product withdrawal should further research prove clinical and cost ineffectiveness. ${ }^{4}$ NICE has the ability to issue guidance to recommend 'only in research', but this is not routinely used and rarely if ever for medical devices. ${ }^{35}$

\section{Strengths and weaknesses}

This is the first research study we have identified that clearly reports the temporal changes in the use of relatively costly wound care products in the UK community over several years. These simple data show powerfully how new products can be adopted rapidly despite a lack of robust evidence for clinical or cost-effectiveness. This reinforces the complex nature of decision making in wound care and importance of other spheres of information and knowledge including expert opinion and peerto-peer advice. ${ }^{29}$ The role of marketing and company activity in successfully promoting product use is also an area that may have had impact here although this would need to be explored in further work. ${ }^{36}$

Our analysis of wound care prescribing is limited by the available data. Temporal changes in dressing use and expenditure may also be influenced by demographic and epidemiological factors (eg, an ageing population and the rise in chronic diseases such as diabetes). ${ }^{37}$ The prescribing data are not wound-specific and limited to English community prescriptions; however, we note that the community is where most complex wounds are treated. ${ }^{38}$ We also note that prescribing data will not include data on those standard dressings that are kept as stock. ITS analysis has been used to explore the possible impact of the first significant national clinical guideline, the SIGN guideline, on the management of venous leg ulcers. There is a suggestion of some impact of this 'intervention'; however, it has to be noted (as above) that this guidance is specific to venous leg ulcers whereas the PCA data cover dressing use for any wound type. These analyses did not include multiple 'interventions' incorporating the publication of other guidelines as it was decided to 
use the single intervention point of 2010 for reasons stated in the methods. However, presenting a summary of the general status of evidence (table 1), which is so consistent in its message helps provides important contextual information in which to interpret the data.

A limitation of the ITS design is that any hypothesised relationship between the implementation of guidelines and changes in dressing use is based purely on a temporal association. We have no direct evidence of causation. Furthermore, the ordinary least squares model forecasts linear trends, yet the post-SIGN trends for antimicrobial dressings do not appear to be linear and show a reversal of the initial decreasing trend from 2012. This is partly explained by the differences in use of silver and other antimicrobial dressings (see online supplementary appendix 1F). As future data become available, it will be important to monitor the use of antimicrobial dressings in case further intervention is needed to reduce use. However, these changes are temporarily distant from the SIGN guidance and the primary aim of the ITS analysis was to examine changes occurring around the time of the SIGN guidance.

\section{Conclusions}

This paper suggests that in the last 20 years there has been a large increase in the use of antimicrobial wound dressings despite a lack of research evidence to support their routine use. Expenditure on antimicrobial wound dressings has risen by over £28 million between 1997 and 2016.

Our analysis shows that routinely available PCA data can be used to identify unproven products with a significant net financial burden to the NHS. These data may offer a transparent and systematic route to 'only in research' and ultimately to deimplementation. If using routine data in this way is to have an impact on prescribing at scale, then it needs to be linked to a multilevel response that targets procurement processes alongside individual practices to ensure increased value and reduced waste.

\section{Author affiliations}

${ }^{1}$ Division of Nursing, Midwifery and Social Work, School of Health Sciences, Faculty of Biology, Medicine and Health, University of Manchester, Manchester, UK

${ }^{2}$ NIHR CLAHRC Greater Manchester, Salford Royal NHS Foundation Trust, Salford, UK ${ }^{3}$ Division of Population Health, Health Services Research and Primary Care, School of Health Sciences, Faculty of Biology, Medicine and Health, Centre for Epidemiology, University of Manchester, Manchester, UK

${ }^{4}$ Alliance Manchester Business School, University of Manchester, Manchester, UK ${ }^{5}$ Research and Innovation Division, Manchester University NHS Foundation Trust, University of Manchester, Manchester, UK

Contributors $\mathrm{LH}$ is the first author of manuscript and helped in data analysis. SJS interrupted time series analysis and interpretation. PW contributed to interpretation of data and manuscript revision. JCD helped study concept and design, interpretation of data and manuscript revision. NC contributed to interpretation of data and manuscript revision.

Funding This research was conducted as part of the Collaboration for Leadership in Applied Health and Care Excellence Greater Manchester (CLAHRC GM), a programme of research funded with the National Institute for Health Research (NIHR) infrastructure.

Competing interests None declared.
Patient consent for publication Not required.

Provenance and peer review Not commissioned; externally peer reviewed.

Data availability statement Data are available in a public, open access repository.

Open access This is an open access article distributed in accordance with the Creative Commons Attribution Non Commercial (CC BY-NC 4.0) license, which permits others to distribute, remix, adapt, build upon this work non-commercially, and license their derivative works on different terms, provided the original work is properly cited, appropriate credit is given, any changes made indicated, and the use is non-commercial. See: http://creativecommons.org/licenses/by-nc/4.0/.

\section{REFERENCES}

1. Abbasi K. How to get better value healthcare. J R Soc Med 2007;100:480.

2. Porter ME. What is value in health care? N Engl $\mathrm{J}$ Med 2010;363:2477-81.

3. Prasad V, Vandross A, Toomey C, et al. A decade of reversal: an analysis of 146 contradicted medical practices. Mayo Clin Proc 2013;88:790-8.

4. Prasad V, loannidis JP. Evidence-Based de-implementation for contradicted, unproven, and aspiring healthcare practices. Implement Sci 2014;9.

5. Elshaug AG, Watt AM, Mundy L, et al. Over 150 potentially lowvalue health care practices: an Australian study. Med J Aust 2012;197:556-60.

6. Friman A, Klang B, Ebbeskog B. Wound care in primary health care: district nurses' needs for co-operation and well-functioning organization. J Interprof Care 2010;24:90-9.

7. Dhivya S, Padma VV, Santhini E. Wound dressings - a review. Biomedicine 2015;5.

8. Cullum N, Grey T, Rhodes S, et al. Opportunities for better value health care. In Press 2017.

9. Cohen D, Billingsley M. Europeans are left to their own devices. BMJ 2011;342:2748.

10. The new regulations on medical Devices-Medical devices: regulatory framework, 2018. Available: http://ec.europa.eu/growth/sectors/ medical-devices/regulatory-framework_en [Accessed 25 Mar 2019].

11. Chronic wounds: advanced wound dressings and antimicrobial dressings. National Institute of Health \& Care Excellence, 2016.

12. Dumville JC, Petherick ES, O'Meara S, et al. How is research evidence used to support claims made in advertisements for wound care products? J Clin Nurs 2009;18:1422-9.

13. Knowles A. Dressings: Is there an evidence base? In: Boulton AJM, Cavanagh PR, Rayman G, eds. The Foot in Diabetes. 4th edn. John Wiley \& Sons Ltd, 2006.

14. Prescription cost analysis, 2017. Available: https://digital.nhs.uk/ data-and-information/publications/statistical/prescription-costanalysis [Accessed 25 Mar 2019].

15. British National Formulary (BNF): wound management products and elasticated garments, 2017. Available: https://bnf.nice.org.uk/woundmanagement/ [Accessed 25 Mar 2019].

16. Scottish Intercollegiate Guidelines Network (SIGN). Management of chronic venous leg ulcers. A national clinical guideline. 120th edn, 2010.

17. Michaels JA, Campbell WB, King BM, et al. A prospective randomised controlled trial and economic modelling of antimicrobial silver dressings versus non-adherent control dressings for venous leg ulcers: the VULCAN trial. Health Technol Assess 2009;13:1-114.

18. Linden $A$. Conducting interrupted time-series analysis for single- and Multiple-group comparisons. Stata J 2015;15:480-500.

19. Bullock I, Collins C, Cullum N, et al. Clinical Practice guidelines: the nursing management of patients with venous leg ulcers. The Royal College of Nursing, 2006.

20. Chopra I. The increasing use of silver-based products as antimicrobial agents: a useful development or a cause for concern? $\mathrm{J}$ Antimicrob Chemother 2007;59:587-90.

21. Lay-flurrie K. Honey in wound care: effects, clinical application and patient benefit. Br J Nurs 2008;17:S30-S36.

22. Vermeulen $\mathrm{H}$, Westerbos SJ, Ubbink DT. Benefit and harm of iodine in wound care: a systematic review. J Hosp Infect 2010;76:191-9.

23. Gemmell CG, Edwards DI, Fraise AP, et al. Guidelines for the prophylaxis and treatment of methicillin-resistant Staphylococcus aureus (MRSA) infections in the UK. J Antimicrob Chemother 2006;57:589-608.

24. Sheldon TA, Cullum N, Dawson D, et al. What's the evidence that NICE guidance has been implemented? Results from a national 
evaluation using time series analysis, audit of patients' notes, and interviews. BMJ 2004;329.

25. Lau R, Stevenson F, Ong BN, et al. Achieving change in primary care-causes of the evidence to practice gap: systematic reviews of reviews. Implementation Sci 2015;11.

26. Murthy L, Shepperd S, Clarke MJ, et al. Interventions to improve the use of systematic reviews in decision-making by health system managers, policy makers and clinicians. Cochrane Database Syst Rev 2012:CD009401.

27. Luker KA, Kenrick M. An exploratory study of the sources of influence on the clinical decisions of community nurses. J Adv Nurs 1992:17:457-66.

28. McCaughan D, Thompson C, Cullum N, et al. Nurse practitioner and practice nurses' use of research information in clinical decision making: findings from an exploratory study. Fam Pract 2005;22:490-7.

29. Gray T, Wilson P, Dumville JC, et al. What factors influence community wound care? A focus group study using the theoretical domains framework 2018. doi: 10.1136/bmjopen-2018-024859. [Epub ahead of print 31 July 2019].

30. Wang V, Maciejewski ML, Helfrich CD, et al. Working smarter not harder: coupling implementation to de-implementation. Health Care 2018;6:104-7.

31. Vermeulen H, Ubbink DT, de Zwart F, et al. Preferences of patients, doctors, and nurses regarding wound dressing characteristics: a conjoint analysis. Wound Repair Regen 2007:15:302-7.

32. Levinson W, Kallewaard M, Bhatia RS, et al. 'Choosing wisely': a growing international campaign. BMJ Qual Saf 2015;24:167-74.
33. Choosing wisely UK, 2019. Available: https://www.choosingwisely. co.uk/ [Accessed 25 Mar 2019].

34. Rothery C, Claxton K, Palmer S, et al. Characterising uncertainty in the assessment of medical devices and determining future research needs. Health Econ 2017;26:109-23.

35. Longworth L, Youn J, Bojke L, et al. When does NICE recommend the use of health technologies within a programme of evidence development?: a systematic review of NICE guidance. Pharmacoeconomics 2013;31:137-49.

36. Madden M. Alienating evidence based medicine vs. innovative medical device marketing: a report on the evidence debate at a wounds conference. Soc Sci Med 2012;74:2046-52.

37. Dowsett C, Bielby A, Searle R. Reconciling increasing wound care demands with available resources. J Wound Care 2014;23:552-62.

38. Gray TA, Rhodes S, Atkinson RA, et al. Opportunities for better value wound care: a multiservice, cross-sectional survey of complex wounds and their care in a UK community population. BMJ Open 2018;8:e019440.

39. Vermeulen $\mathrm{H}$, van Hattem JM, Storm-Versloot MN, et al. Topical silver for treating infected wounds. Cochrane Database Syst Rev 2007:CD005486.

40. Jull AB, Cullum N, Dumville JC, et al. Honey as a topical treatment for wounds. Cochrane Database Syst Rev 2015:CD005083.

41. Pressure ulcers: prevention and management Clinical guideline [CG179]: National Institute for Health and Care Excellence. NICE, 2014.

42. NICE guidance: Diabetic foot problems:prevention and management. NICE, 2015 